\title{
Ethylene Biosynthesis and Polyamine and ABA Levels in Cut Carnations Treated with Aminotriazole
}

\author{
María Serrano and $\mathrm{M}^{\mathrm{a}}$ Concepción Martínez-Madrid \\ Escuela Politécnica Superior (Universidad Miguel Hernández), Ctra. Beniel, Km 3.2, \\ Orihuela (Alicante), Spain \\ Félix Romojaro \\ Centro de Edafología y Biología Aplicada del Segura (CSIC), Avda. La Fama 1, Murcia, Spain
}

\begin{abstract}
AdDitional INDEX wORDs. abscisic acid, ABA, aminotriazole, Dianthus caryophyllus, ethylene, polyamines, senescence
Abstract. Treatment of cut 'Master' carnations (Dianthus caryophyllus L.) with 50 mm aminotriazole (ATA) in distilled water for 5 days retarded senescence, increased flower longevity by 4 days compared to the control carnations kept in distilled water and inhibited the climacteric peak of ethylene production normally produced during the senescence of these flowers. The treatment had no effect, however, on the levels of the polyamines putrescine and spermidine. Thus, the biosynthetic routes of ethylene and polyamines may not compete for the common precursor $S$-adenosylmethionine (SAM). Also, in the petals of the control carnations, increased ethylene production was correlated with increased ion leakage and abscisic acid (ABA) levels. In the ATA treated petals, ion leakage and ABA levels increased later and reached values less than $50 \%$ compared to the control carnations. Chemical names used: abscisic acid (ABA), 3-1H-amino-1,2,4-triazole-1yl (aminotriazole), 1-aminocyclopropane-1-carboxylic acid (ACC), $S$-adenosyl methionine (SAM).
\end{abstract}

Most cultivated carnations behave as climacteric organs in which ethylene biosynthesis and respiration rate increase in association with the beginning of senescence (Van Altvorst and Bovy, 1995). Ethylene is synthesized from the amino acid methionine through the conversion of $S$-adenosylmethionine (SAM) into 1aminocyclopropane-1-carboxylic acid (ACC) and the subsequent oxidation of ACC to yield ethylene. The final two reactions are catalyzed by ACC synthase and ACC oxidase, respectively (Yang and Hoffman, 1984), which increase their expression during senescence (Woodson et al,. 1992). SAM is also a precursor for the synthesis of the polyamines spermidine and spermine. Ethylene and polyamines are thought to have opposite effects on fruit ripening and senescence; ethylene is the hormone of senescence, while polyamines are considered to be related to young or actively growing tissues (Kakkar and Rai, 1993; Tiburcio et al., 1997). The fact that ethylene and polyamines have a common precursor and that they appear to have opposing physiological roles, has led various investigators to suggest that both routes are able to compete for this common precursor (Casas et al., 1990; Dibble et al., 1988; Toumadje and Richardson, 1988).

For quite some time it has been known that several compounds inhibit the biosynthesis or action of ethylene and that these compounds are useful in prolonging the longevity of cut carnations (reviewed by Van Altvorst and Bovy, 1995). It has been reported recently that continuous postharvest treatment of carnations with 50 or $100 \mathrm{~mm}$ aminotriazole (ATA) results in a significant extension of useful vase life, suppressed respiration, inhibition of the climacteric rise in $\mathrm{CO}_{2}$ and differential time and concentration dependent floral responses to exogenous ethylene (Altman and Solomos, 1993). ATA is a low molecular weight heterocyclic ring

Received for publication 30 Mar. 1998. Accepted for publication 1 Oct. 1998. This rechearch was financially supported by the Consejería de Agricultura Medio Ambiente y Agua de la Región de Murcia, project PS96CAB2. We thank J.C. Pech (ENSAT, Toulouse, France) and M. Vendrell (CID-CSIC, Barcelona, Spain) for their critical revision of the manuscript. The cost of publishing this paper was defrayed in part by the payment of page charges. Under postal regulations, this paper therefore must be hereby marked advertisement solely to indicate this fact. compound, and is currently marketed for use as a postemergence, nonselective systemic herbicide (Sine et al., 1991). ATA is known to inhibit a variety of cellular metabolic processes including peroxisomal assembly of tetrameric catalase apoenzyme, $\mathrm{CO}_{2}$ assimilation, mitochondrial protein biosynthesis, and the biosynthesis of imidazolglycerol-phosphate dehydratese, an enzyme of histidine biosynthesis in bacteria and fungi (Altman and Solomos, 1994; Amory et al., 1992). However, ATA is not a general metabolic poison, since it does not inhibit enzymes such as ascorbate peroxidase and glutathione reductase (Amory at al., 1992). Altman and Solomos (1994) reported that ATA inhibits ethylene biosynthesis by inhibiting ACC synthase biosynthesis and the autostimulatory effect of ethylene, with the latter being temporally mediated. ATA has been classified as a putative carcinogen (Sine et al., 1991), so its commercialization as a cut-flower preservative is difficult. Nevertheless, its ability to inhibit ethylene biosynthesis makes it useful for physiological investigations aimed at studying the control of senescence processes in the absence of this hormone.

The objective of this study was to determine if inhibition of the biosynthesis of ACC synthase by ATA would increase levels of the polyamines spermidine and spermine, which would indicate that both pathways, ethylene and polyamine biosynthesis, compete for their common precursor. In addition we analyzed the levels of abscisic acid (ABA), a hormone also related to maturation, especially in nonclimacteric fruit (Kondo and Inoue, 1997), and senescence of carnation flowers in both control and ATA treated carnation flowers, in order to determine the role of $\mathrm{ABA}$ in controlling carnation senescence when ethylene is inhibited.

\section{Materials and Methods}

Plant material. Cut 'Master' carnations were obtained from a local greenhouse in Puerto Lumbreras (Murcia, Spain) during the winter of 1997 in a state of commercial opening (with the petals forming an angle of $120^{\circ}$ with the base of the calyx). Once in the laboratory, the flowers were trimmed to a $15-\mathrm{cm}$ stem length, 
randomized, and placed individually in test tubes containing distilled water (control) or ATA $(50 \mathrm{~mm})$. This moment was considered to be day 0 of the experiment. Treatment with ATA lasted for $5 \mathrm{~d}$, after which the treated flowers were put in distilled water. The environmental conditions maintained throughout the experiment were: temperature 20 to $22^{\circ} \mathrm{C}$, relative humidity $(\mathrm{RH})$ $75 \%$ to $80 \%$ in a $12 \mathrm{~h}$ photoperiod using white fluorescent light $\left(74.5 \mu \mathrm{mol} \cdot \mathrm{s}^{-1} \cdot \mathrm{m}^{-2}\right)$. Every $2 \mathrm{~d}$, three carnations were taken from the distilled water and ATA treatments, and ion leakage, polyamines and ABA levels were determined from their petals. Ten carnations kept in water and another 10 treated with ATA were used for measuring ethylene production daily throughout the experiment.

Ethylene production. To measure the ethylene production, cut carnations were individually enclosed in 500-mL glass jars fitted with a silicon septum for $1 \mathrm{~h}$. After this time a 1-mL sample of the jar atmosphere was withdrawn, and the ethylene concentration determined using a gas chromatograph (model 5890; HewlettPackard) equipped with a flame ionization detector (FID) and a 3$\mathrm{m}$ length stainless-steel column with a 3.17-mm inner diameter, filled with 80/100 activated alumina (Serrano et al., 1991). Results were expressed as nanoliters of ethylene produced per gram of fresh weight per hour $\left(\mathrm{nL} \cdot \mathrm{g}^{-1} \cdot \mathrm{h}^{-1}\right)$, and are the mean \pm SE of determinations made independently in 10 flowers.

ION LEAKAGE. Ten petal discs were incubated in $40 \mathrm{~mL}$ of 0.11 M mannitol, with agitation, for $3 \mathrm{~h}$. The conductivity of the mannitol solution was then measured with a CRISON CM 2200 conductimeter (Alella Barcelona, Spain) (Serek et al., 1995). The discs were then frozen, maintained at $-20{ }^{\circ} \mathrm{C}$ for $24 \mathrm{~h}$ and then heated in an autoclave at $125^{\circ} \mathrm{C}$ for $1 \mathrm{~h}$. Finally, the conductivity of the mannitol solution was measured again and considered as $100 \%$ ion leakage. The rate of ion leakage was then expressed as a percentage of the total conductance following petal destruction (Serek et al., 1995). Two determinations were made independently from each carnation.

Polyamine eXtraction AND Quantification. Polyamines were extracted with $\mathrm{HClO}_{4}$ and analyzed by the benzoylation method as previously reported by Serrano et al. (1991). Extracts for polyamine analysis were prepared by homogenizing five carnation petals in 5 $\mathrm{mL}$ of $5 \% \mathrm{HClO}_{4}$ using a mortar and pestle. The homogenate was then centrifuged for $30 \mathrm{~min}$ at $20,000 \mathrm{~g}_{\mathrm{n}}$ and $2 \mathrm{~mL}$ of the supernatant was mixed with $2 \mathrm{~mL}$ of $4 \mathrm{M} \mathrm{NaOH}$ and $20 \mathrm{~mL}$ of benzoyl chloride in an appropriate glass tube. After vortexing for $15 \mathrm{~s}$, the mixture was incubated for $20 \mathrm{~min}$ at room temperature. Saturated $\mathrm{NaCl}$ and cold diethyl ether ( $4 \mathrm{~mL}$ each) were then added. After that the tube content was vortexed for $15 \mathrm{~s}$ and incubated for $30 \mathrm{~min}$ at $-18^{\circ} \mathrm{C}$. Finally, $2 \mathrm{~mL}$ of the ether phase that contained benzoylpolyamines were evaporated under nitrogen and redissolved in 1 mL of methanol (HPLC grade). Benzoyl-polyamines were analyzed by HPLC using a Waters system (Waters Associates, Milford, Mass.). The elution system consisted of methanol: water (64:36, v/v as solvent), run isocratically with a flow rate of 0.8 $\mathrm{mL} \cdot \mathrm{min}^{-1}$. The benzoyl-polyamines were eluted through a reversephase column (LiChroCart 250-4, $5 \mu \mathrm{m}$; Merck, Darmstadt, Germany) and detected by absorbance at $254 \mathrm{~nm}$. A relative calibration procedure was used to determine the amounts of polyamines in samples using standard curves of putrescine, spermidine and spermine from Sigma (Poole, Dorset, England) and adding hexanediamine as the internal standard. Two extractions of polyamines were made from each carnation, and results were expressed as nmol per gram of fresh weight and are the mean $\pm \mathrm{SE}$ of these two determinations made independently in each one of the three carnations.

Aba ACID Determination. All determinations were carried out in dim light. ABA was extracted from five petal samples with $5 \mathrm{~mL}$ of a solution of $80 \%$ acetone containing $100 \mathrm{mg} \cdot \mathrm{L}^{-1}$ of butylated hydroxytoluene and $0.5 \mathrm{~g} \cdot \mathrm{L}^{-1}$ of citric acid. The extracts were suitably diluted with a $50 \mathrm{~mm}$ Tris buffer, $\mathrm{pH} 7.8$, containing $1 \mathrm{~mm}$ $\mathrm{MgCl}_{2}$ and $150 \mathrm{~mm} \mathrm{NaCl}$ and then quantified by an enzyme-linked immuno-sorbent assay (ELISA), using an IgG monoclonal antibody (Idetek, Inc. San Bruno, Calf.), as previously reported (Martínez-Madrid et al., 1996). For each carnation flower, two extractions were made and $\mathrm{ABA}$ content was estimated from the standard curve prepared for each particular plate. For each extract four dilutions were made, and at least three of them fell on the standard curve. The ABA levels were consistent with the dilution made and no interference from impurities was detected when ABA standards were added to diluted extracts. Results are expressed as pmol per gram of fresh weight and are the mean \pm SE of two extractions made independently in each one of the three flowers, and each extract quantified in quadruplicate.

\section{Results}

Ethylene Production. In the control cut carnations, ethylene production was very low during the first $10 \mathrm{~d}$ at $20^{\circ} \mathrm{C}$ (Fig. 1). Autocatalytic ethylene production was initiated on day 10 and reached a maximum of $\approx 30 \mathrm{~nL} \cdot \mathrm{g}^{-1} \cdot \mathrm{h}^{-1}$ at day 12 , followed by a sharpe decline. Maximum ethylene production coincided with the appearance of visible symptoms of senescence of the flower, such as petal inrolling and withering. Based on these results, it was considered that the longevity of the control carnations was $12 \mathrm{~d}$.

In contrast, for those carnations treated with ATA for $5 \mathrm{~d}$, the ethylene production was very low $\left(0.80\right.$ to $\left.1.85 \mathrm{~nL} \cdot \mathrm{g}^{-1} \cdot \mathrm{h}^{-1}\right)$ through to complete withering of the flowers. ATA completely inhibited the climacteric peak of ethylene production (Fig. 1). In the ATA treated carnations, the longevity was $16 \mathrm{~d}$. In addition to the symptoms of senescence shown in the control flowers, ATA treated carnations developed necrotic lesions at the petal edges. In previous experiments we had observed that treatments of cut

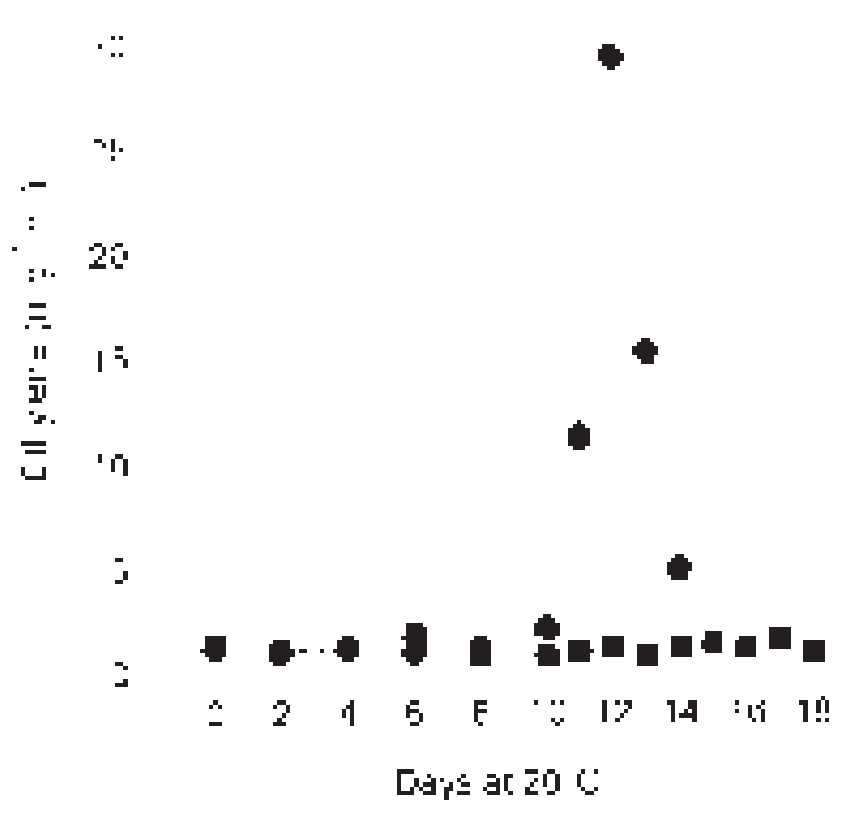

Fig. 1. Ethylene production (fresh weight basis) of ATA-treated carnations $(\boldsymbol{\square})$ and control ones kept in distilled water $(\mathbf{O})$. Data are the mean \pm SE of the determinations made independently in 10 flowers. 


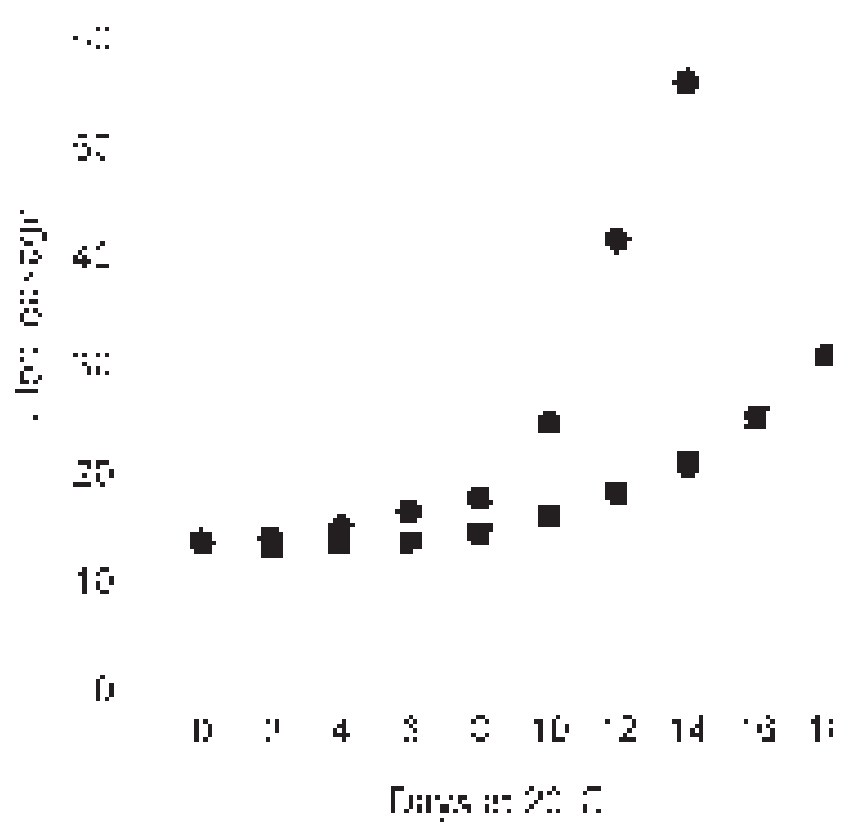

Fig. 2. Ion leakage (\%) from petals of ATA-treated cut carnations ( $\mathbf{\square})$ and controls kept in distilled water $(\mathcal{O})$. Data are the mean \pm SE of two determinations made independently in each of the three flowers.

carnations with $100 \mathrm{~mm}$ ATA for $3 \mathrm{~d}$ were able to prolong vase life and inhibit ethylene production, whereas the 10-mm treatment only inhibited ethylene production when the flowers were kept in this solution until the end of their senescence (unpublished data).

ION LEAKAGE. The percent ion leakage in the control carnations did not significantly change during the first days of storage at $20^{\circ} \mathrm{C}(14 \%$ to $16 \%$ ) and increased slightly from day 8 . The increase become more pronounced between days 10 and 14, reaching a maximum at the end of the flower's life when the petals had totally deteriorated (Fig. 2). In carnations treated with ATA, the increase in percent ion leakage began to appear at day 10 but was much less pronounced, reaching values of $30 \%$ at the end of the conservation period, compared to the $56 \%$ reached in the control carnations (Fig. 2).

Polyamine levels. The major polyamines in the carnation

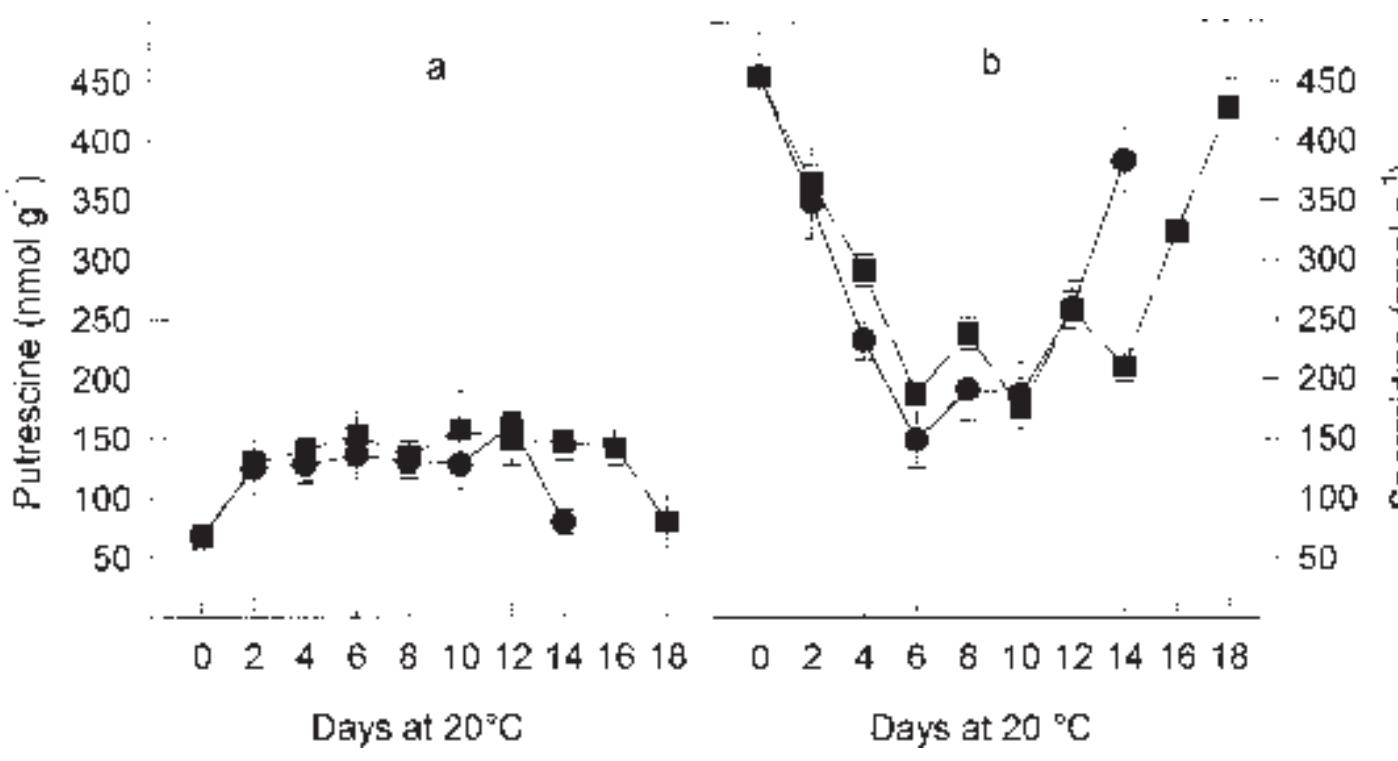

petals were putrescine and spermidine. The level of spermine was very low, just on the limit of, and in some cases below detectable limits. In recently harvested carnations, the spermidine level was $454.7 \mathrm{nmol} \cdot \mathrm{g}^{-1}$, substantially greater than that of putrescine $(67.5$ $\left.\mathrm{nmol} \cdot \mathrm{g}^{-1}\right)$. As senescence progressed, a clear increase in putrescine level was noted, while the opposite was observed for the spermidine level (Fig. 3a and b). During the last stages of senescence, a pronounced decrease in the putrescine level and an increase in spermidine was observed. Significant differences did not exist between the levels of these polyamines between control carnations and those treated with ATA, except that the changes detected at the end of senescence were produced $4 \mathrm{~d}$ apart, beginning earlier in the control carnations than in those treated with ATA (Fig. 3a and b).

LEVELS OF ABA. Levels of ABA in the control carnations were very low and did not show significant changes during the first $6 \mathrm{~d}$ of conservation of the carnations in distilled water. From day 8 they increased suddenly, coinciding with the appearance of the first symptoms of senescence in the petals, and continued increasing until the end of the life of the flowers, reaching values of 190.7 pmol.g ${ }^{-1}$ (Fig. 4). In the ATA treated carnations, this increase began to be significant from day 12 and the level of ABA at the end of the life of these carnations was $99.4 \mathrm{pmol} \cdot \mathrm{g}^{-1}$, considerably lower than the level found in the control carnations (Fig. 4).

\section{Discussion}

The results obtained from this work showed that treatment with $50 \mathrm{~mm}$ ATA for $5 \mathrm{~d}$ increased the longevity of cut carnations by 4 d. Altman and Solomos (1993) also showed that 50 or $100 \mathrm{~mm}$ ATA applied continuously to cut carnations prolonged useful vase life, inhibiting physiological and morphological aspects of carnation senescence relative to flowers kept in distilled water. ATA completely inhibited the autocatalytic production of ethylene observed in the control carnations, probably due to an inhibition of the synthesis of the enzyme ACC synthase (Altman and Solomos, 1994). If the pathways of ethylene and polyamine biosynthesis compete for their common precursor SAM, it would be expected that in the carnations treated with ATA, in which the diversion of SAM towards ethylene is blocked, the levels of spermidine and spermine should be greater than those found in the control carnations. However, the results obtained show similar levels of these polyamines, in the control and ATA treated carnations (Fig. 3a and b), the only difference being that the reduction in putrescine and the increase in spermidine produced in the last phases of senescence occurred $4 \mathrm{~d}$ earlier in the control carnations than in those treated. As such, it seems that under these conditions the routes of ethylene and polyamines are regulated indepen-

Fig. 3.Putrescine(a) andspermidine (b) levels (fresh weight basis) of petals during senescence of cut carnations kept in ATA (ם) or in distilled water $(\mathbf{O})$. Results are the mean \pm SE of two determinations made independently in each of the three flowers. 


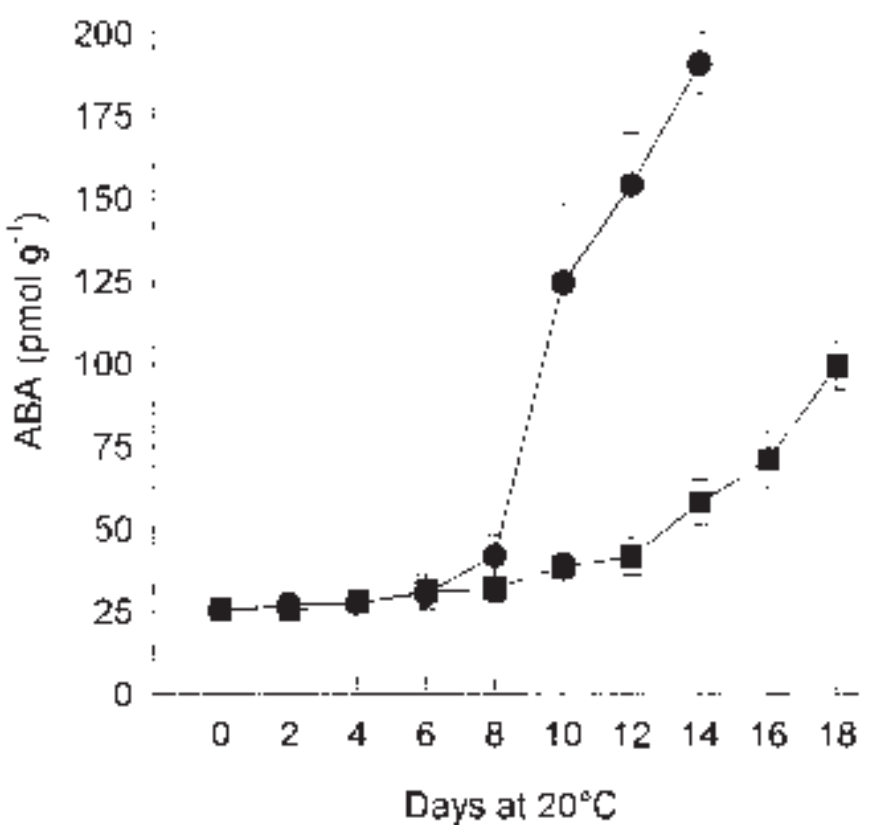

Fig. 4. ABA levels (fresh weight basis) of petals during senescence of carnations kept in ATA (ם) or in distilled water (). Results are the mean \pm SE of two extractions made independently in each of the three flowers and each one quantified in quadruplicate.

dently, without direct competition for SAM. Another possibility would be that treatment with ATA truly provokes an increase in these polyamines, but that they are rapidly conjugated (Walden et al., 1997) and therefore were not detected in this study in which only free polyamines were measured.

The relationship between ethylene and polyamines biosynthetic pathways is not clear, and contradictory results have been found. Matoo et al. (1993) showed that polyamines inhibited ACC synthase expression and activity in tomato, whereas ethylene inhibited the biosynthesis of polyamines in Daucus carota L. cells (Roustan et al., 1992) but stimulated it in wounded green banana fruit (Musa AAA group, Cavendish subgroup 'Giant Cavendish') (Yoza et al., 1996). Experimental evidence also exists indicating that blocking the conversion of SAM to polyamines increases the ethylene biosynthesis in potato (Solanum tuberosum L.) plants with antisense SAM-decarboxylase (Kumar et al., 1996) and in carnation flowers treated with MGBG, an inhibitor of SAM decarboxylase activity (Serrano, 1990). However in transgenic cantaloupe (Cucumis melo L.) melons with an ACC oxidase antisense gene, an inhibition of ethylene biosynthesis was observed without any increase in spermidine level (Guis, 1997). These findings, as well as our results, support the idea that inhibition of the polyamine biosynthesis pathway results in a greater ethylene biosynthesis but that the opposite may not be the case.

On the other hand, a close temporal relationship has been observed between an increase in the biosynthesis of ethylene and the electrolyte leakage, which is an indication of deterioration of the cellular membranes. The major damage to the membranes appears to be a lateral phase separation of lipids in the bilayer. This in turn leads to the formation of discrete gel and liquid crystalline phase lipid domains, which leads to the stimulation of the lipiddegrading enzymes (Paliyath and Thompson, 1990). However, the value of IL reached in those carnations treated with ATA at the end of their senescence was half of that found in the control carnations, which may indicate that inhibiting ethylene production also preserves the integrity of the membrane, as has been suggested to occur in rose petals senescence (Faragher et al., 1987).

$\mathrm{ABA}$ has for years been thought to play a major role in the regulation of flower senescence and previous studies have attempted to correlate an endogenous increase in $\mathrm{ABA}$ with a rise in ethylene production (Eze et al., 1986; Hanley and Bramlage, 1989). However, the synchronous behavior of these two hormones in senescing carnation petals has made it difficult to assess their respective roles in relation to the physiological process. We have found increased ABA levels in ATA-treated carnations during senescence, without any rise in ethylene production, which indicates a separation of the relationship between these two hormones. Nevertheless, the ABA level reached in ATA treated carnation was lower than that in control ones, which might indicate an inhibition of ABA biosynthesis by ATA either directly or by an ethylene mediated effect.

\section{Literature Cited}

Altman, S.A. and T. Solomos. 1993. 3-Amino-1,2,4-triazole prolongs carnation vase life. HortScience 28:201-203.

Altman, S.A. and T. Solomos. 1994. Inhibition of ethylene biosynthesis and action in cut carnations (Dianthus caryophyllus L.) by aminotriazole. J. Amer. Soc. Hort. Sci. 119:282-287.

Amory, A.M., L. Ford, N.W. Pammenter, and C.F. Cresswell. 1992. The use of 3-amino-1,2,4-triazole to investigate the short-term effects of oxygen toxicity on carbon assimilation by Pisum sativum seedlings. Plant Cell Environ. 15:655-663.

Casas, J.L., M. Acosta, J.A. Del Río, and F. Sabater. 1990. Ethylene evolution during ripening of detached tomato fruit: Its relation with polyamine metabolism. Plant Growth Regul. 9:89-96.

Dibble, A.R.G., P.J. Davies, and M.A. Mutschler. 1988. Polyamine content of long-keeping alcobaca tomato fruit. Plant Physiol. 86:338340.

Eze, J.M.O., S. Mayak, J.E. Thompson, and E.B. Dumbroff. 1986. Senescence in cut carnation flowers: Temporal and physiological relationships among water status, ethylene, abscisic acid and membrane permeability. Physiol. Plant. 68:323-328.

Faragher, J.D., E. Wachtel, and S. Mayak. 1987. Changes in the physical state of membrane lipids during senescence of rose petals. Plant Physiol. 83:1037-1042.

Guis, M. 1997. Transformation génétique du melon cantaloup Charentais. Caractérisation de melons transgéniques exprimant un gène antisens de l'ACC oxydase. PhD diss. Inst. Natl. Polytech. de Toulouse, France.

Hanley, K.M. and W.J. Bramlage. 1989. Endogenous levels of abscisic acid in aging carnation flower parts. J. Plant Growth Regul. 8:225-236.

Kakkar,R.K. and V.K. Rai. 1993. Plant polyamines in flowering and fruit ripening. Phytochemistry 33:1281-1288.

Kondo, S. and K. Inoue. 1997. Abscisic acid (ABA) and 1aminocyclopropane-1-carboxylic acid (ACC) content during growth of Satohnishiki cherry fruit, and the effect of ABA and ethephon application on fruit quality. J. Hort. Sci. 72:221-227.

Kumar, A., M.A. Taylor, S.A. Mad Afrid, and H.V. Davies. 1996. Potato plant expressing antisense and sense SAMDC transgenes show altered levels of polyamines and ethylene: Antisense plants display abnormal phenotypes. Plant J. 9:147-158.

Martínez-Madrid, M.C., M. Serrano, F. Riquelme, and F. Romojaro. 1996. Polyamines, abscisic acid and ethylene production in tomato fruit Phytochemistry 43:323-326.

Mattoo, A.K., N. Li, and D. Liu. 1993. Tomato ACC synthase: Regulation of gen expression and importance of C-terminal region in enzyme activity, p. 223-231. In: J.C. Pech, A. Latché, and C. Balagué (eds.). Cellular and molecular aspects of the plant hormone ethylene. Kluwer Academic Publ.

Paliyath, G. and J.E. Thompson. 1990. Evidence for early changes in 
membrane structure during post-harvest development of cut carnation (Dianthus caryophyllus L.) flowers. New Phytol. 114:555-562.

Roustan, J.P., A. Latché, and J. Fallot. 1992. Influence of ethylene on the incorporation of 3,4-[ $\left[{ }^{14} \mathrm{C}\right]$ methionine into polyamines in Daucus carota cells during somatic embryogenesis. Plant Physiol. Biochem. 30:201205.

Serek, M., G. Tamari, C. Sisler, and A. Borochov. 1995. Inhibition of ethylene-induced cellular senescence symptoms by 1-methylcyclopropene, a new inhibitor of ethylene action. Physiol. Plant. 94:229-232.

Serrano, M. 1990. Metabolismo y acción del etileno durante la senescencia y conservación de varias especies florales. PhD diss. Univ. Murcia, Spain.

Serrano, M., F. Romojaro, J.L. Casas, and M. Acosta. 1991. Ethylene and polyamine metabolism in climacteric and nonclimacteric carnation flowers. HortScience 26:894-896.

Sine, C., N. Fisher, and F. Valahovski (eds.). 1991. Farm chemicals handbook. Meister Publ., Willoughby, Ohio. p. C20.

Tiburcio, A.F., T. Altabella, A. Borrel, and C. Masgrau. 1997. Polyamine metabolism and its regulation. Physiol. Plant. 100:664-674.

Toumadje, A. and D.G. Richardson. 1988. Endogenous polyamine concentrations during development, storage and ripening of pear fruits. Phytochemistry 27:335-338.

Van Altvorst, A.C. and A.G. Bovy. 1995. The role of ethylene in the senescence of carnation flowers, a review. Plant Growth Regul. 16:4353.

Walden, R., A. Cordeiro, and A.F. Tiburcio. 1997. Polyamines: Small molecules triggering pathways in plant growth and development. Plant Physiol. 113:1009-1013.

Woodson, W.R., K.Y. Park, A. Drory, P.B. Larsen, and H. Wang. 1992. Expression of ethylene biosynthetic pathway transcript in senescing carnation flowers. Plant Physiol. 99:526-532.

Yang, S.F. and N.E. Hoffman. 1984. Ethylene biosynthesis and its regulation in higher plants. Annu. Rev. Plant Physiol. 35:155-189.

Yoza, K.-I., Y. Takeda, K. Sekiya, Y. Nogata, and H. Ohta. 1996. Putrescine accumulation in wounded green banana fruit. Phytochemistry 42:331-334. 